\title{
A Study of the Internal Boundary Layer Generated at the Alcantara Space Center
}

\author{
Luciana Bassi Marinho Pires ${ }^{1}$, Gilberto Fisch ${ }^{2, *}$, Ralf Gielow ${ }^{1}$, Leandro F. Souza ${ }^{3}$, \\ Ana Cristina Avelar ${ }^{2}$, Igor Braga De Paula ${ }^{4}$, Roberto Da Mota Girardi ${ }^{5}$ \\ ${ }^{1}$ Center for Numerical Weather Forecast and Climatic Studies (CPTEC), National Institute for Space Research (INPE), São José dos \\ Campos, Brazil \\ ${ }^{2}$ Institute of Aeronautics and Space (IAE-ACA), Department of Science and Aerospace Technology (DCTA), São José dos Campos, Brazil \\ ${ }^{3}$ Department of Applied Mathematics and Statistics (ICMC), University of São Paulo (USP), São Carlos, Brazil \\ ${ }^{4}$ Department of Mechanical Engineering, Pontifical Catholic University of Rio de Janeiro (PUC-RJ), Rio de Janeiro, Brazil \\ ${ }^{5}$ Aeronautics Technology Institute (ITA), Department of Science and Aerospace Technology (DCTA), São José dos Campos, Brazil
}

\begin{abstract}
An atmospheric Internal Boundary Layer (IBL) occurs when sudden changes in surface roughness disturb wind flows. The region of the Brazilian Alcantara Space Center (ASC), with its rocket launching pad located $150 \mathrm{~m}$ downwind of a $40 \mathrm{~m}$ coastal cliff, presents the formation of an IBL due to winds blowing inland from the ocean. Numerical simulations using the immersed boundary method, experiments in a wind tunnel using particle image velocimetry, and field observational data obtained from anemometric towers were used to study this IBL. The results demonstrated that it is dependent on the geometry of the coastal cliff: its height is around 17 and $15 \mathrm{~m}$ for slopes of the coastal cliff of $90^{\circ}$ and $135^{\circ}$, respectively. The numerical results show a good agreement with the experimental data and the field observations, but with an overestimation of the vorticity field. The IBL significantly influences the wind flow at the launching pad.
\end{abstract}

Keywords Alcantara Space Center, Immersed boundary method, Particle image velocimetry, Anemometric tower, Wind tunnel

\section{Introduction}

The main concern of a rocket launching platform is safety. This is the primary reason that platforms are built on islands, with the launchings directed to the ocean. Additional concerns include measurement of wind and gusts and scheduling launchings for those times when there are favorable weather conditions, making the work of the meteorologist among the most important during the launching process. In addition to (i) the problems that lightening can cause (electrical surges can trigger loss of control and cause destruction of rockets); (ii) the formation of fog and ice on the vehicle due the temperature and humidity fields; (iii) turbulence that can impose unacceptable stresses on key structural elements and (iv) wind that can affect the electronic guidance system, the rockets can also be affected by turbulence when positioned at the ramp, prior to the launch [1]. All these aspects make the behavior of winds and atmospheric turbulence, especially in the superficial boundary layer, to be objects of great interest in Aerospace Meteorology, because their

* Corresponding author:

fisch.gilberto@gmail.com (Gilberto Fisch)

Published online at http://journal.sapub.org/ajee

Copyright $(2015$ Scientific \& Academic Publishing. All Rights Reserved characteristics provide basic information for both Research \& Development (R\&D) of rockets and analysis of the ambient conditions in the case of failed launchings, as shown by (i) Uccellini et al. [2] and Fichtl et al. [3] concerning the explosion of the Space Shuttle Challenger in 1986, (ii) Winters et al. [4] and Bellue et al. [5] regarding Columbia's problem during its reentry flight and (iii) Kingwell et al. [6] pertaining to weather factors affecting rocket operations. Wind data are also necessary for calculation of rockets' trajectories; for a typical Brazilian rocket launching, up to the height of $1000 \mathrm{~m}, 88 \%$ of the corrections in the trajectory are due to the wind, while above $5000 \mathrm{~m}$ this influence falls to $3 \%$ [7].

Concerning rocket activities, Johnson [8], for example, provides a complete compilation of the main climatic elements at the US Space Launching Centers, and Vaughan and Johnson [9] describe the lessons learned by working on aerospace meteorology during the last 50 years. Know et al. [10], using a wind tunnel, performed an experiment to study the atmospheric conditions of the island of Oenaro-Do, in order to facilitate the design of the Korean Space Center.

In Brazil, the main spaceport is located near the Atlantic ocean, at the Alcântara Space Center (ASC), on the coast of Maranhão ( $\left.2^{\circ} 19^{\prime} \mathrm{S} ; 44^{\circ} 22^{\prime} \mathrm{W}, 40 \mathrm{msl}\right), 30 \mathrm{~km}$ from São Luiz (Fig. 1). It presents a coastal cliff with an abrupt change in roughness (from a smooth oceanic surface to a 
rough continental surface), associated with a topographical step of $40 \mathrm{~m}$ due to the cliff. The wind blowing from the ocean, initially in balance with its surface, interacts with the coastal cliff and the continental shrubbery vegetation, here with a $4 \mathrm{~m}$ average tree height, thus producing an Internal Boundary Layer (IBL) and its associated turbulence. The rocket launching pad (RLP) is located at $150 \mathrm{~m}$ from the edge of this coastal cliff (Fig. 2). So, the launchings may be significantly influenced by the local IBL. Based on this assumption the objective of the present work is to show and compare different techniques to understand the IBL flow close to the ASC.

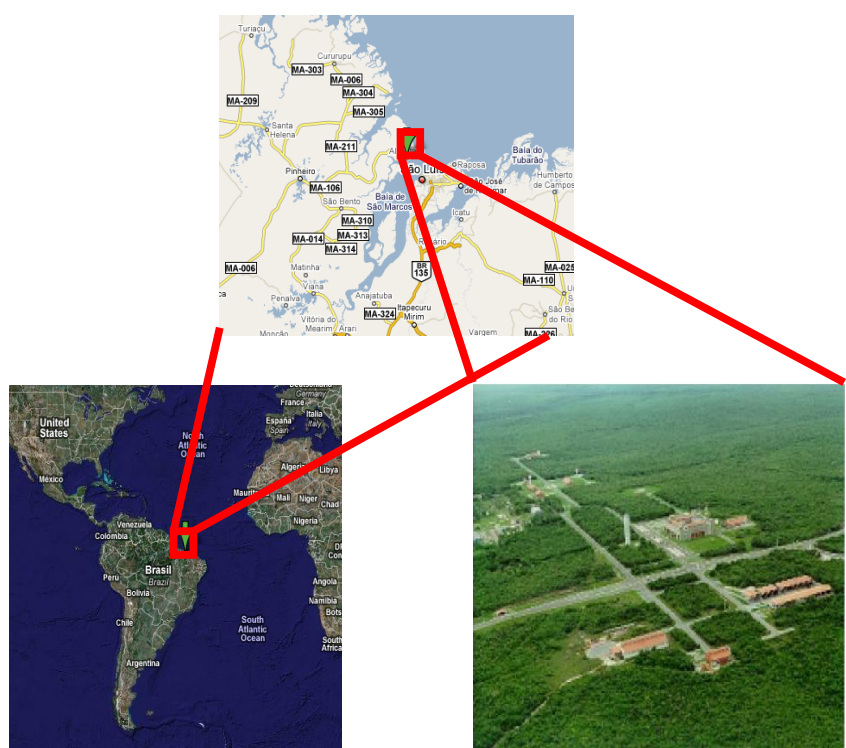

Figure 1. Localization at the Alcantara Space Center (ASC)

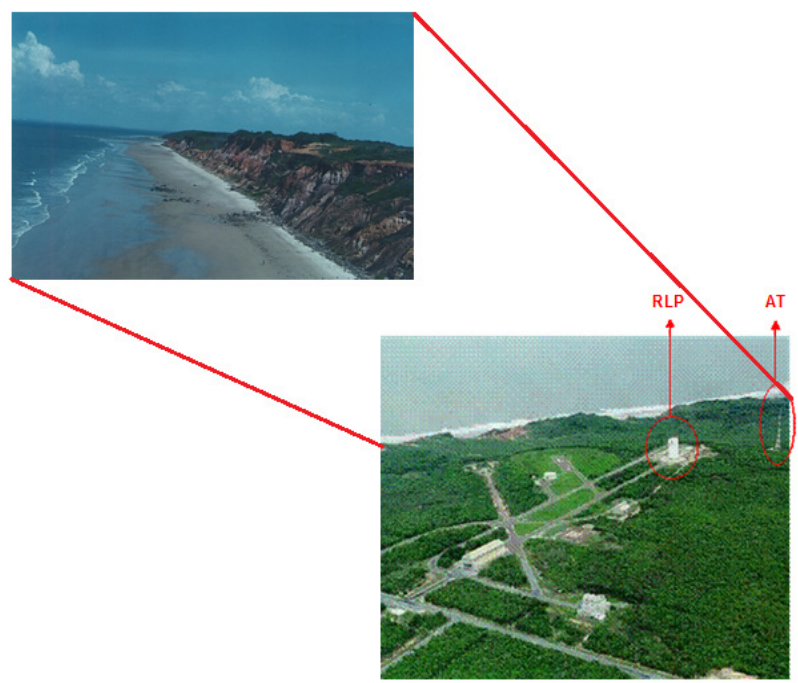

Figure 2. Coastal cliff, anemometric tower (AT) and rocket launching pad (RLP) localizations at the ASC

The flow from the ocean must first surmount a cliff before it flows over the point of interest. The primary objectives here are to compare the results from the different techniques (numerical simulations, wind tunnel experiments and observational micrometeorological tower data) used to study atmospheric wind profiles and vorticity fields, as well as to quantify the height of IBL developed downwind of a coastal cliff and analyze how these parameters can affect the RLP.

\section{Literature Review}

A preliminary survey on the structure of the wind at the ASC, using an anemometric tower $70 \mathrm{~m}$ in height, with sensors for speed and wind direction at six levels, 6.0, 10.0, $16.3,28.5,43.0$ and $70.0 \mathrm{~m}$ respectively, was conducted by Fisch [7], demonstrating that the winds are more intense in the dry season, with typical values between $5.0 \mathrm{~m} \mathrm{~s}^{-1}$ at the height of $6 \mathrm{~m}$ and $9.0 \mathrm{~m} \mathrm{~s}^{-1}$ at $70 \mathrm{~m}$, because of the occurrence of coupling of trade winds with the movement of sea breezes. In the rainy season, in which the position of the Intertropical Convergence Zone is predominant in the characterization of the local climate, the wind in the ASC typically ranges from $3.0 \mathrm{~m} \mathrm{~s}^{-1}$ at $6 \mathrm{~m}$ height to $5.0 \mathrm{~ms}^{-1}$ at $70 \mathrm{~m}$. Fisch [11], using a three-dimensional sonic anemometer, installed on a mast of $9 \mathrm{~m}$ localized near the RLP, in the period of August 4 through 27, 1999, characteristic of the dry season, and from April 11 through June 19, 2003, which are representative of the wet season, found that the winds are more intense in the dry season, being about $1.0 \mathrm{~m} \mathrm{~s}^{-1}$ stronger than during the rainy season, without dependence on the stability, except for the maximum wind, which occurs in the stability-instability transition in the dry season; during the rainy season the opposite transition occurs. In 2005, Fisch [12] analyzed the behavior of the wind profile in the ASC under neutral conditions, with data collected as described in Fisch [7]. The friction velocity $u *$ was very peculiar, due to the seasonal variation of the wind, which is stronger in September than in March. In March $u *$ showed a value of $0.21 \mathrm{~m} \mathrm{~s}^{-1}$ and in September, $0.43 \mathrm{~m} \mathrm{~s}^{-1}$. The roughness length $\mathrm{z}_{0}$ was between $0.66 \mathrm{~m}$ (March) and $0.77 \mathrm{~m}$ (September). The wind profiles observed ranged from $1.2 \mathrm{~m} \mathrm{~s}^{-1}$ (level 1 of $6 \mathrm{~m}$ ) to $2.5 \mathrm{~m} \mathrm{~s}^{-1}$ (level 6 of $70 \mathrm{~m}$ ) in March, and from $2.2 \mathrm{~m} \mathrm{~s}^{-1}$ (level 1) to 4.8 $\mathrm{m} \mathrm{s}^{-1}$ (level 6) in September. These results were generally lower than those obtained for the ASC for these months, as shown in Fisch [7]. Data of friction velocity $u_{*}$, aerodynamic roughness length $z_{0}$, the mean velocity profiles and turbulent intensity in the ASC were also studied by Roballo and Fisch [13] and Roballo et al. [14]. In the first study, Roballo and Fisch [13] determined from observations of the anemometer tower $70 \mathrm{~m}$ from the ASC, that the $u *$ is equal to $0.32 \pm 0.13$ $\mathrm{m} \mathrm{s}^{-1}$ (rainy season) and $0.46 \pm 0.11 \mathrm{~m} \mathrm{~s}^{-1}$ (dry season), while the roughness length $z_{0}$ is equal to $0.19 \pm 0.32 \mathrm{~m}$ (rainy season) and $0.06 \pm 0.05 \mathrm{~m}$ (dry season). Thus the seasonality of wind profiles was demonstrated. The exponent $\alpha$ of the power law was also obtained for the velocity ranging from 0.19 to 0.27 over the months of the year, with correlation coefficients $\left(R^{2}\right)$ between 0.88 and 0.99 , decreasing with height $z$. The validation of $\alpha$ with wind data from 2004 through 2005 showed that in the rainy months, estimated local velocities are greater than observed ones, perhaps due 
to weaker atmospheric neutrality, however, in a dry month, they were equivalent, demonstrating the neutral atmospheric conditions. In the second study Roballo et al. [14] used wind tunnel measurements with the hot wire anemometer method. The characteristics of detachment and subsequent reattachment of the flow were observed, as well the recirculation bubbles and the turbulent structure on the top of the coastal cliff. These results were shown qualitatively due to the low Reynolds number $(\mathrm{Re})$ reached for the wind tunnel $\left(10^{4}\right.$ order) that did not correspond to the real atmospheric Reynolds number of the order of $10^{7}$.

The speed up of the flows over different geometries also has been the subject of many studies. Jackson and Hunt [15] and Britter et al. [16] analyzed the changes in the wind speed related to the size and shape of the hill and to the roughness of the surface using two-dimensional measurements in the wind tunnel and in the field and observed the increase of wind speed over the hill top. The three-dimensional experiments developed by Hunt and Snyder [17] and Hunt et al. [18] over a hill with stable and neutral stratified flow nicely showed the internal hydraulic jumps and regions of separated-flow of the structure formed around the hill in a diffusion equation analysis. In this case the recirculation zone occurs behind the hills. A similar study about the streamlines generated for stably stratified flow over a three-dimensional hill was developed by Snyder et al. [19]. Different shapes, upwind density and velocity profiles were tested to distinguish the streamlines which pass around the hill from those that pass over it, according to the Sheppard's simple energy argument [20]. In the case of coastal cliffs the streamlines pass just over the cliff and no separation occurs. However, the influence of the coastal cliff on the flow corresponds in some respects to the well-known forward facing step (FFS) engineering paradigm. Sherry et al. [21] studied the behavior of the FFS immersed in a turbulent boundary, using water channel and wind tunnel experiments. However, the emphasis of the current paper is determining the height of the IBL, in contrast with the engineering perspective focusing on the reattachment length and the height of the recirculation region as described in Sherry's work. Another engineering focus considers the regions of separation of the flow over the step. Pearson et al. [22] used High-speed Particle Image Velocimetry (PIV) to investigate the relationship between the upstream and downstream regions of separation in the FFS.

\subsection{Internal Boundary Layer}

The influence of the new surface on the wind flow depends not only on its own characteristics, but also on the characteristics of the previous surface, over which the flow previously was in balance. So, a new equilibrium layer is formed (IBL), whose vertical thickness increases with the distance from the edge (Fig.3). Above this new layer the wind profile remains in balance with the previous surface, while inside it, the wind profile is adjusted to the new surface
[23]. For ASC, the IBL is generated both by the surface characteristics and the presence of the coastal cliff. The thickness of the IBL may be defined as the height above ground where the wind velocity reaches a specified fraction (0.90 or 0.99 ) of its upstream equilibrium value [24].

Several theoretical and experimental studies, such as Elliot [25], Pendergrass and Arya [26], Sempreviva et al. [27], Sugita and Brutsaert [28], Källstrand and Smedman [29], Jegede and Foken [30] and Savelyev and Taylor [31], especially address the problem of neutral flow over an area of change of the step roughness in a flat surface, focusing on the development of the modified wind profile, the response of the turbulent field and on the growth of the IBL. Savelyev and Taylor [31] present a table with expressions of the height of the IBL presented for 20 works starting from Elliot [25]. Non-neutral situations, considering convection, according Jegede and Foken [30], can be covered with adjustments in the neutral empirical coefficients. Subsequently attention turned to the effects of thermal stratification on the flow, growth and structure of the convective thermal IBL related to changes in temperature and heat flux at the surface [32], as shown in Batchvarova and Gryning [33] Liu et al. [34] and Hara et al. [35]. Loredo-Souza et al. [36] have suggested that for wind speeds greater than $10 \mathrm{~ms}^{-1}$, the flow is turbulent enough to neglect thermal effects. Jackson and Hunt [15], in their studies near the surface of the hill, also affirm that although stratification has an important effect on wind, there are many instances when high winds occur and stratification has only a small effect on the flow. In work developed by Roballo and Fisch [13] it was shown that the atmospheric boundary layer at ASC can be treated as being neutral most of the time. In studies conducted at the Bolund peninsula in Denmark, Berg et al. [37] also determined that atmospheric stratification can be neglected for practical purposes, since the flow perturbations induced by changes in stability are smaller than those caused by hills.

According to a number of field and laboratory observations under neutral stability conditions, the growth of the internal boundary layer thickness $(\delta)$ follows an approximate power law, which was first proposed by Elliot [25]:

$$
\frac{\delta_{I B L}}{z_{o 2}}=a_{I B L} \cdot\left(\frac{x}{z_{o 2}}\right)^{b_{I B L}}
$$

where $x$ is the distance from the edge of the surface discontinuity, $z_{02}$ is the downwind aerodynamic roughness length and $a_{I B L}$ and $b_{I B L}$ are constants that depend on the surface roughness. Empirical values for $a_{I B L}$ vary from 0.35 to 0.75 , and for $b_{I B L}$ range from 0.1 , for smooth surfaces, to 0.4 , for urban areas [24]. It is worthwhile to notice that this formula may not be used for distances beyond $1-2 \mathrm{~km}$ from the coast, where the growth of the IBL height reaches an asymptotic value [29]. 


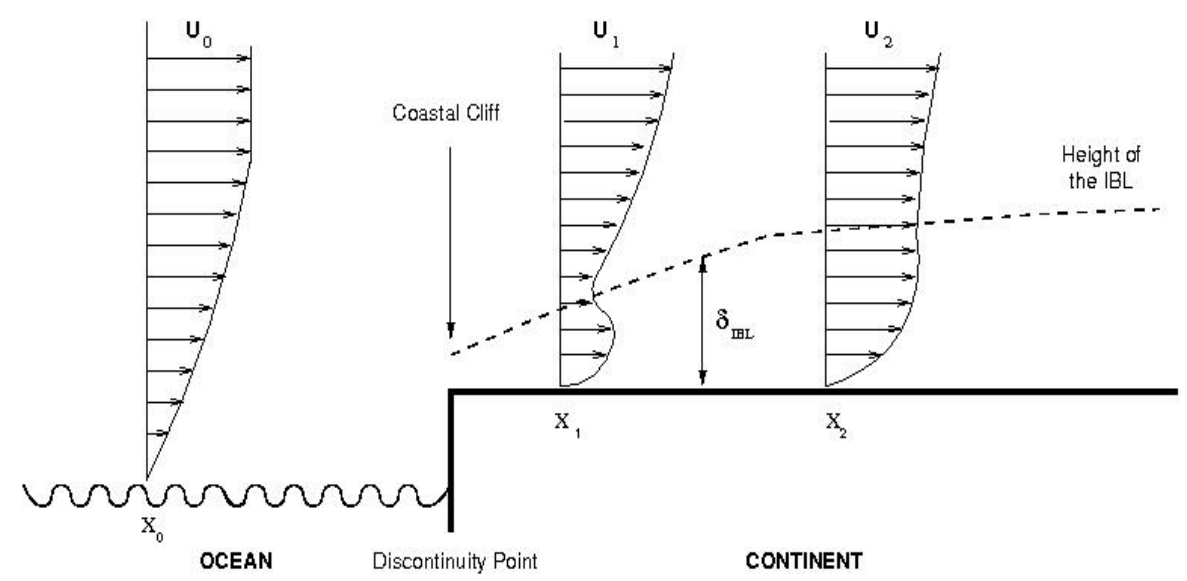

Figure 3. Development of the IBL downwind of an ocean cliff and wind profiles over oceanic $\left(x_{0}\right)$ and continental $\left(x_{1}\right.$ and $\left.x_{2}\right)$ positions

In this paper, we define $\delta_{I B L}$ as the height when the vertical derivative $(z)$ of the vorticity $\omega$ becomes practically zero, which corresponds to an $\omega$ profile which is almost constant and an approximately linear variation of velocity with height, as is the case of the Planetary Boundary Layer (PBL) above the IBL.

\section{Methodology}

\subsection{Observational Data}

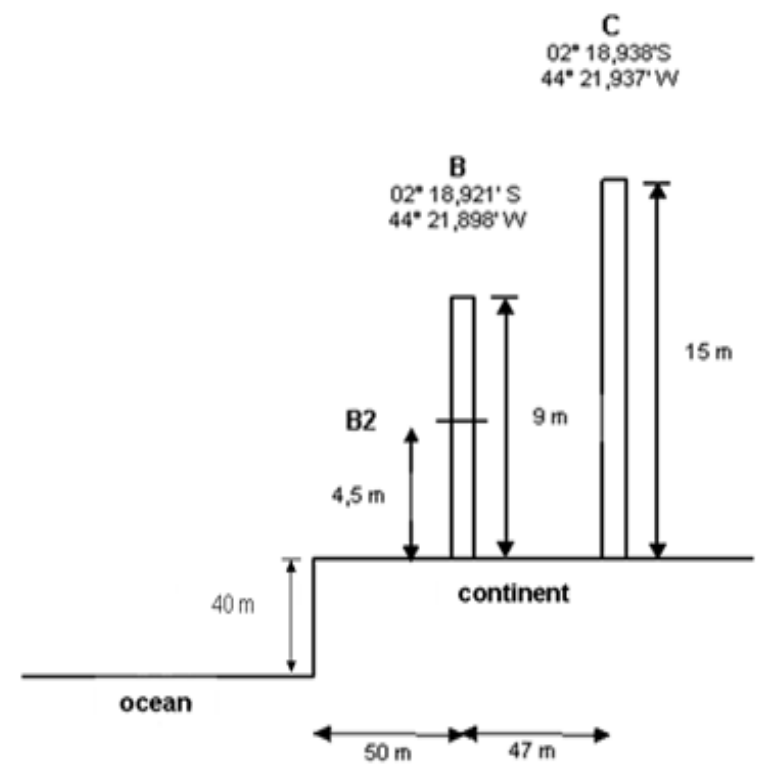

Figure 4. Schematic representation of the anemometers during ECLICLA's campaigns; in ECLICLA 2 was added the B2

Two observational data sets were analyzed:

(i) Wind velocity and direction on a $70 \mathrm{~m}$ anemometric tower (AT), located $200 \mathrm{~m}$ downwind of the coastal cliff, measured over several years at six levels: 6.0, 10.0, 16.3, 28.5, 43.0 and $70.0 \mathrm{~m}$;

(ii) The field campaigns near the edge of the cliff: ECLICLA 1 (April 14-24, 1998, representing the wet season) and ECLICLA 2 (October, 6-16, 1998, representing the dry season). ECLICLA is the Portuguese acronym for "Estudos da Camada Limite Interna na região do CLA" which means the study of the IBL at the ASC. The anemometers (aerovanes from R.M. Young) for both campaigns were installed on two masts on the continent downwind of the cliff: $\mathrm{B}-50 \mathrm{~m}$ and $\mathrm{C}-100 \mathrm{~m}$, at the heights of $9 \mathrm{~m}$ and $15 \mathrm{~m}$, respectively for $\mathrm{B}$ and C; for ECLICLA 2, an extra anemometer (B2) was added at the height of $4.5 \mathrm{~m}$ of the mast B (Fig. 4).

\subsection{Wind Tunnel Experiments}

The wind tunnel (WT) experiments were made at the Prof. Kwein Lien Feng Laboratory of the Technological Institute of Aeronautics (ITA), in São José dos Campos, Brazil. This WT is an open conventional subsonic type. The test section is a square window box $(465 \times 465 \mathrm{~mm} 2)$ with a length of $1200 \mathrm{~mm}$. For this study, a channel apparatus with a width of $410 \mathrm{~mm}$ and length of $1200 \mathrm{~mm}$, consisting of an uncovered wooden frame, with free edges and side walls parallel to each other and perpendicular to the floor of the wind tunnel, was used to extend the test section for the formation of the atmospheric Boundary Layer (ABL) based on the roughness correspondent to the rural terrain. Details about this simulation can be found at Pires et al. [38]. The atmospheric flow was simulated by electric fans with $30 \mathrm{hp}(22 \mathrm{~kW})$ power, which generated a maximum wind velocity of $33 \mathrm{~m}$ s-1. The maximum velocity actually reached was between 27 and $30 \mathrm{~m} \mathrm{~s}-1$, corresponding to a Reynolds number (Re) ranging between 7.2 and $8.0 \times 104$ based on the height of the cliff of $40 \mathrm{~m}$. In the atmosphere, the Re is basically of the order of 107 [39]. This Re was also obtained in Bolund, based on hill height and a velocity equal to $10 \mathrm{~m} \mathrm{~s}-1$ [37]. For ASC, it ranged from 1.6 to $2.6 \times 107$, based on the height of the cliff $(\mathrm{H})$ and the wind velocity $(\mathrm{V})$ at the top of the boundary layer (estimated between 200 and $300 \mathrm{~m}$ by Pires et al [40] and approximately $300 \mathrm{~m}$ by Reuter et al. [41]).

Figure 5 presents the dimensions in the wind tunnel of the scaled $(1: 1000)$ cliff and the RLP, represented by a wooden block of $10 \times 10 \times 50 \mathrm{~mm}^{3}$, installed at the centerline. To 
verify the influence of the geometry of the cliff, experiments were made with inclinations of $90^{\circ}, 110^{\circ}$ and $135^{\circ}$. It is wellknown that the direction of winds relative to the shoreline also influences the inland seabreeze and IBL [42]. So this situation was studied considering the wind flow in a perpendicular situation, as well as $45^{\circ}$ rotations to the right and the left. The $45^{\circ}$ angle corresponds to the dominant NE wind at ASC, as determined by Roballo and Fisch [13].

a) $90^{\circ}, 110^{\circ}$ and $135^{\circ}$ inclinations

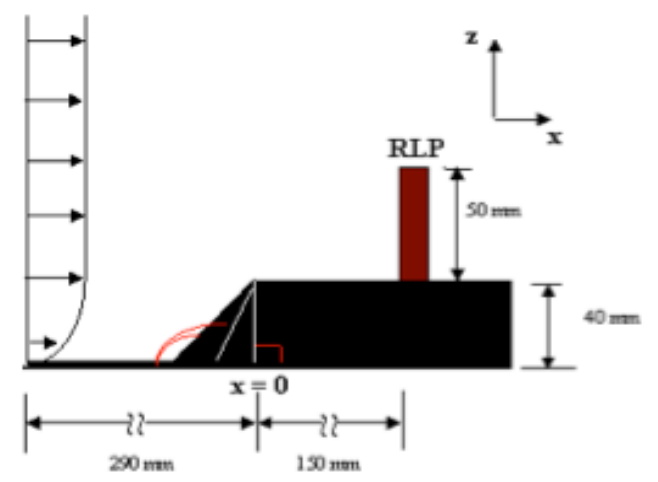

b) $45^{\circ}$ rotation
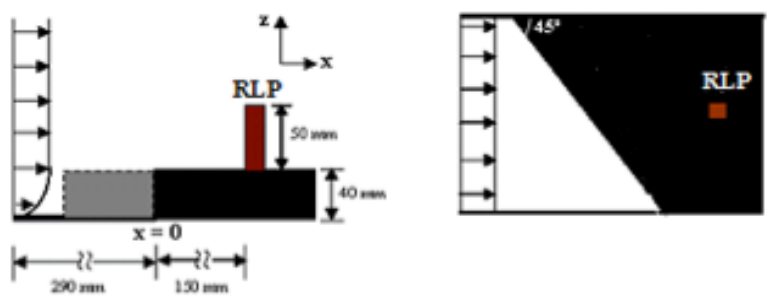

Figure 5. Schematic representation of the scaled models in the wind tunnel (WT)

The atmospheric flow inside the WT was obtained using a two dimensional Particle Image Velocimetry (PIV) system [43]. The test section flow was seeded with smoke particles, approximately $5 \mu \mathrm{m}$ in diameter, using a Rosco Fog generator. A laser Nd-YAG, $200 \mathrm{~mJ} /$ pulse laser of $532 \mathrm{~nm}$ wavelength was employed to illuminate the flow field. To image the flow field, a $60 \mathrm{~mm}$ diameter Nikkor lens was fitted to a 12-bits high-resolution digital camera (Dantec Dynamic HiSense 4M camera) that uses a CCD (Charge Coupled Device) with $2048 \times 2048$ pixels and a $7.4 \mu \mathrm{m}$ pixel pitch. The instantaneous images were processed using the adaptive-correlation option of the commercial software developed by Dantec Dynamics (Flow Manager 4.50.17), and a $32 \times 32$ pixels interrogation window with $50 \%$ overlap and moving average validation was used. More information about this instrument as well as the experimental details of the measurements may be found at Pires [44].

\subsection{Numerical Simulation}

The Navier-Stokes equations for 2D incompressible flows, with constant density and viscosity, with velocity components $\mathrm{u}$ and $\mathrm{v}$, respectively in the flow direction $\mathrm{x}$ and vertical direction $\mathrm{z}$, and the vorticity component $\omega y$, with the inclusion of the immersed boundary condition through the forcing forces $\mathrm{Fx}$ and $\mathrm{Fz}$ [45], and $\mathrm{P}$ being the pressure, are expressed in cartesian orthogonal coordinates as follows:

$$
\begin{gathered}
\frac{\partial u}{\partial t}+u \frac{\partial u}{\partial x}+v \frac{\partial u}{\partial z}=-\frac{\partial P}{\partial x}+\frac{1}{\operatorname{Re}} \nabla^{2} u+F_{x}, \\
\frac{\partial v}{\partial t}+u \frac{\partial v}{\partial x}+v \frac{\partial v}{\partial z}=-\frac{\partial P}{\partial z}+\frac{1}{\operatorname{Re}} \nabla^{2} v+F_{z},
\end{gathered}
$$

together with the continuity equation:

$$
\frac{\partial u}{\partial x}+\frac{\partial v}{\partial z}=0
$$

where $\nabla^{2}=\frac{\partial^{2}}{\partial x^{2}}+\frac{\partial^{2}}{\partial z^{2}}, t$ is time and Re is the Reynolds number given by $\operatorname{Re}=\frac{\overline{U L}}{v}$.

$\bar{L}$ is the height of the cliff, $\bar{U}$ is the wind velocity at the top of the Oceanic Boundary Layer and $v$ is the kinematic viscosity.

Defining the vertical vorticity $\omega_{y}=\frac{\partial u}{\partial z}-\frac{\partial v}{\partial x}$, the vorticity transport equation is:

$$
\frac{\partial \omega_{y}}{\partial t}=-u \frac{\partial \omega_{y}}{\partial x}-v \frac{\partial \omega_{y}}{\partial z}+\nabla^{2} \omega_{y}+\frac{\partial F_{x}}{\partial z}-\frac{\partial F_{z}}{\partial x}
$$

From the vorticity and the continuity equations one obtains a Poisson equation for the velocity $v$ as a function of $\omega_{y}$ :

$$
\frac{\partial^{2} v}{\partial x^{2}}+\frac{\partial^{2} v}{\partial z^{2}}=-\frac{\partial \omega_{y}}{\partial x}
$$

The variables used are dimensionless and are related to the dimensional ones by:

$$
\begin{aligned}
x & =\frac{\bar{x}}{\bar{L}}, \quad z=\frac{\bar{z}}{\bar{L}}, u=\frac{\bar{u}}{\overline{U_{\infty}}}, \quad v=\frac{\bar{v}}{\bar{U}_{\infty}}, \quad t=\frac{\bar{t} \bar{U} \infty}{\bar{L}}, \\
\omega_{y} & =\frac{\bar{L}}{\overline{U_{\infty}}} \overline{\omega_{y}}
\end{aligned}
$$

The variables with an overbar are dimensional. Although the results obtained here where stationary, the mathematical model is non stationary. The adopted code is $2 \mathrm{D}$ and no closure turbulence model was adopted. Future versions of the present code are expected to be able to simulate 3D flows and a subgrid model will be implemented in order to obtain a Large Eddy Simulation code.

The boundary conditions are as follows: at the inflow boundary $\left(x=x_{0}\right)$, the velocity and the vorticity components are specified based on the Blasius boundary layer solution; at the outflow boundary $\left(x=x_{\max }\right)$, the second derivatives of the velocity and of the vorticity components in the $\mathrm{x}$ direction are set to zero; at the upper boundary, the derivative 
of $v$ in the $z$ direction is set to zero and the vorticity is set to decay exponentially to zero.

To investigate the IBL numerically, a technique with a high precision numerical scheme was used. It was constituted by (i) a fourth order Runge-Kutta temporal integrator with small storage and (ii) a high order compact finite differences method in the $x$ and $z$ directions, thus ensuring the quality of the results.

Numerical studies of flows over complex surfaces require grids and codes capable of reproducing the physics of these flows. Usually, the grid coincides with the boundaries; there are methods, however, that use orthogonal cartesian coordinates [46]. The method of immersed boundaries is one of these procedures and was introduced by Peskin [47] for incompressible flows with immersed moving bodies that exerted forces on the flow. The main advantage associated with the immersed boundaries is that the equations are solved in a rectangular domain and the fluid-solid interactions at the boundaries are modeled through an additional forcing term determined by the configuration of the boundaries. by:

The forcing terms used for the cliff boundary were given

$$
\begin{aligned}
& F_{x}(x, z)=\alpha(x, z) r_{t} u(x, z) \\
& F_{z}(x, z)=\alpha(x, z) r_{t} v(x, z)
\end{aligned}
$$

where $r_{t}$ is the relaxation term equal to $-R e$. The variable $\alpha$ determines the location of the immersed boundary - the coastal cliff - and is equal to 0 outside the immersed boundary, and equal to 1 inside. The transition between the two regions is expressed by a Gaussian curve. The height of the IBL is calculated by the $z$ position, where the $z$-derivative of the simulated vorticity becomes nearly zero.

The computation code was developed at the Mathematical and Computational Sciences Institute (ICMC) of the University of São Paulo (USP)/ São Carlos campus and it was adapted to the coastal cliff situation [48]. The computer used was an AMD 64X2 4400 processor + with $3 \mathrm{~Gb}$ ram. The grid size was $305 \times 801$ points, with the distance between two consecutive points in the $\mathrm{x}$ and $\mathrm{y}$ direction equal $\mathrm{dx}=7 \times 10^{-6}$ and $\mathrm{dy}=3.5 \times 10^{-6}$, respectively. The total computational time for each simulation were between 72 and 120 hours, increasing with Reynolds number.

\section{Code Validation}

\subsection{AT Observation and Numerical Simulation Comparison}

The numeric code was validated by comparing the wind profile simulated results for a $90^{\circ}$ coastal cliff, with observational data collected at the anemometric tower. Figure 6 shows the observed and the simulated wind profiles for 4 cases. For $\mathrm{Re}=2 \times 10^{7}$ the bias (simulated minus observed wind profiles) was less than $0.7 \mathrm{~m} \mathrm{~s}^{-1}$, and the root mean square error (rmse) ranges from 0.6 to $0.9 \mathrm{~m} \mathrm{~s}^{-1}$. The negative bias near the surface possibly is caused by the Blasius initiation in the code, causing the velocity profile to be less turbulent. The agreement was very good, especially above a height of $10 \mathrm{~m}$.

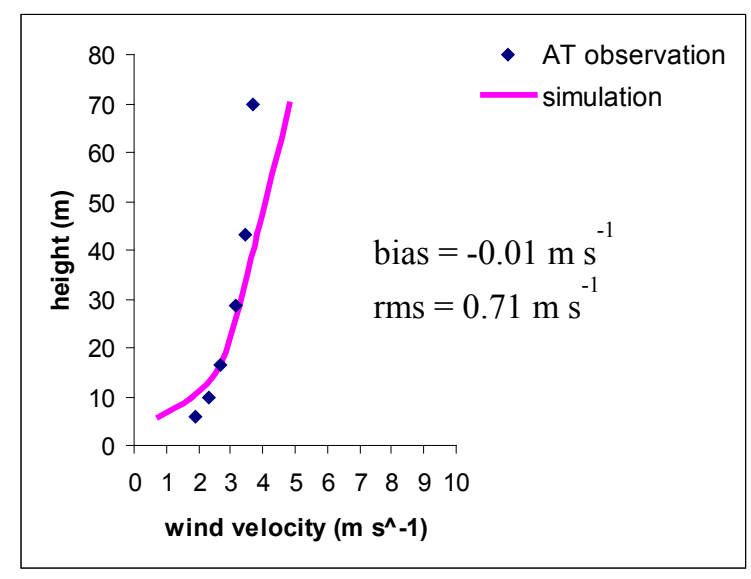

April 29, 1998

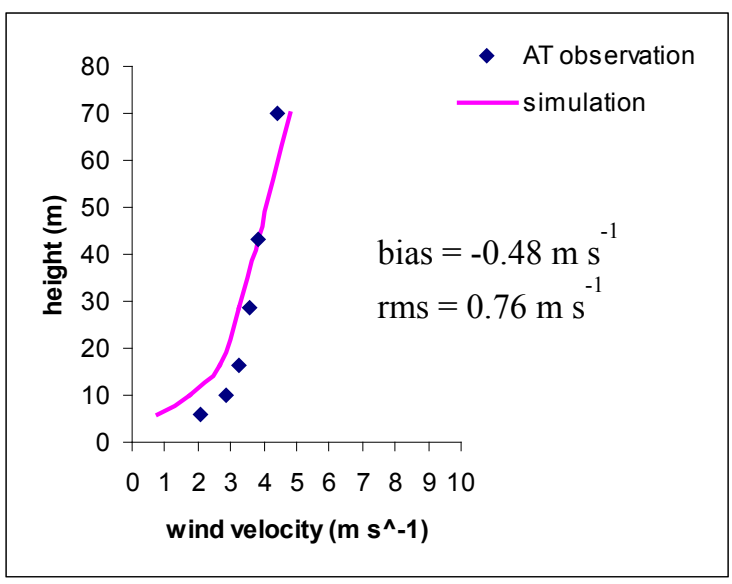

January 27, 1998

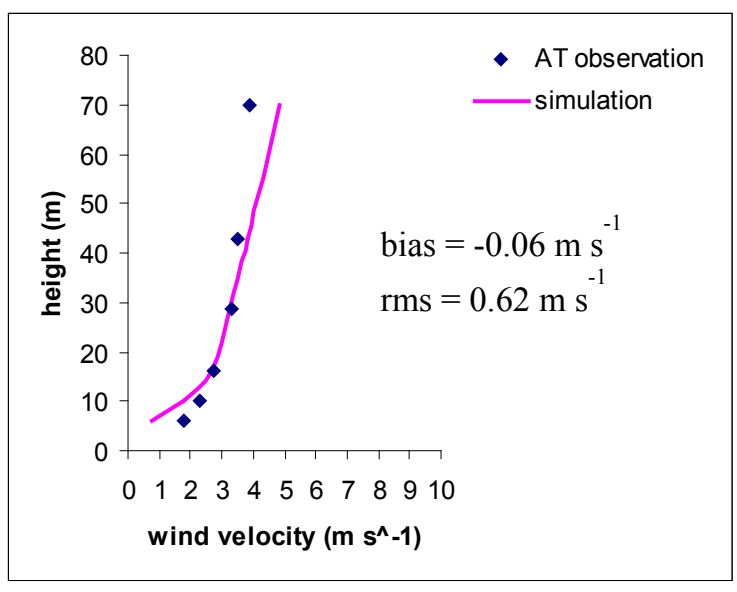

January 24, 2005 


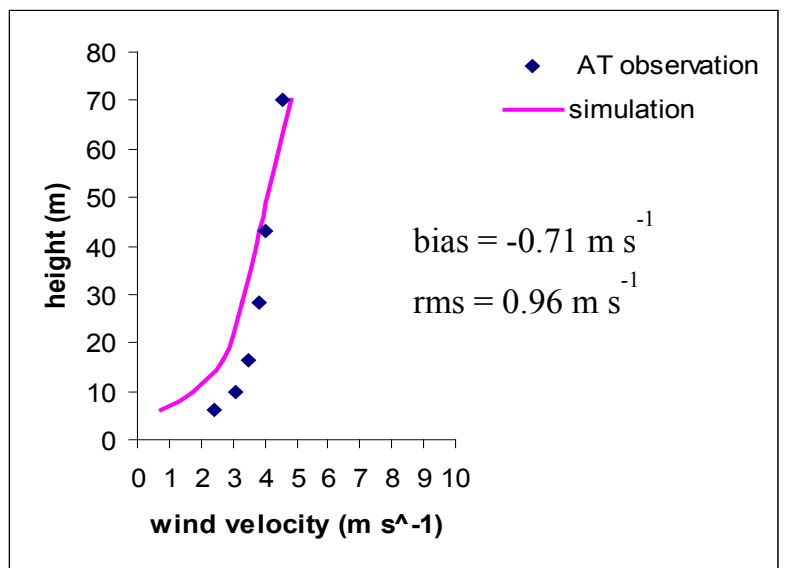

August 02, 2005

Figure 6. Observed and simulated wind profiles at $x=200 \mathrm{~m}$, downwind of a $90^{\circ}$ ocean cliff

\subsection{Wind Tunnel Experiment and Numerical Simulation Comparison for $\operatorname{Re}=7.5 \times 10^{4}$}

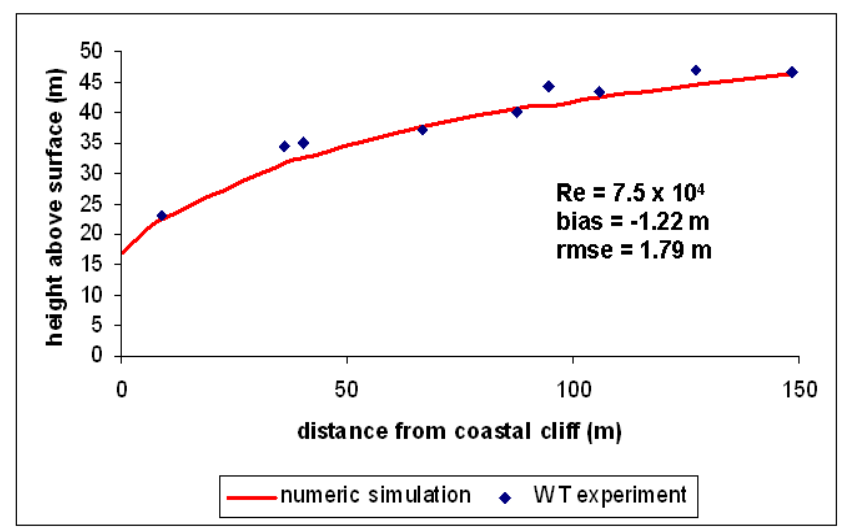

Figure 7. Comparisons between wind tunnel and numerical simulation results

The validation was also performed through comparison with experiments in a wind tunnel. Assuming a wind velocity of $33 \mathrm{~m} \mathrm{~s}^{-1}$, the numerical simulations and experiments were performed with $\mathrm{Re}=7.5 \times 10^{4}$. The heights of the IBL generated by both the WT experiment and the numerical simulation are shown on Figure 7, presenting a rmse of $1.8 \mathrm{~m}$ and a bias of $-1.2 \mathrm{~m}$, which constitutes a reasonable approximation between these results, that is, the numerical simulation represents well the behavior of the IBL formed in the WT. Only the $90^{\circ}$ coastal cliff was considered for the validation.

\section{Results and Discussions}

\subsection{ECLICA 1 and 2}

The wind characteristics during ECLICLA 1 and 2 campaigns, respectively: wind velocity (V) and its standard deviation (SD), maximum wind velocity (Vmax), and turbulent intensity $(\mathrm{I}=\mathrm{SD} / \mathrm{V})$ are shown on Table 1 .

During ECLICLA 1 The highest values of V (around $8 \mathrm{~m}$ s-1) occur on mast B and there is a slightly diurnal cycle: the daytime winds are stronger than in the nocturnal period, with the differences ranging from +0.3 to $+0.4 \mathrm{~ms}-1$. The maximum wind velocity is also stronger at mast $\mathrm{B}$, which also shows lower turbulence. For the ECLICLA 2, the winds (both average and maximum) are stronger during the dry season relative to the ECLICLA 1, and they show the same pattern described earlier. The turbulent intensity (varying between 0.07 and 0.14 ) is stronger for all situations. The values derived from the anemometer B2 are basically the same as the ones observed by anemometer $\mathrm{C}$. This is an indication that $\mathrm{B} 2$ and $\mathrm{C}$ measurements present the same characteristics, while the B measurements are different. Probably the sensor B is measuring the characteristics from the oceanic flow, while both B2 and C are representing the turbulence generated by the change of surface and the presence of the coastal cliff.

Table 1. Wind characteristics from ECLICLA 1 and 2

\begin{tabular}{|c|c|c|c|c|c|c|c|c|}
\hline \multirow{3}{*}{$\begin{array}{c}\text { Time } \\
\text { Local time }\end{array}$} & \multirow{2}{*}{\multicolumn{2}{|c|}{ Anemometers }} & \multicolumn{3}{|c|}{ ECLICLA 1 (E1) } & \multicolumn{3}{|c|}{ ECLICLA 2 (E2) } \\
\hline & & & & $-24,199$ & & Oct. 6 & 16,1998 & Dry \\
\hline & Position & $\begin{array}{l}\text { Height } \\
(\mathrm{m})\end{array}$ & $\begin{array}{l}\mathrm{V}(\mathrm{SD}) \\
(\mathrm{m} \mathrm{s}-1)\end{array}$ & $\begin{array}{l}\text { Vmáx } \\
(\mathrm{m} \mathrm{s}-1)\end{array}$ & $\begin{array}{c}\mathrm{I} \\
(\mathrm{SD} / \mathrm{V})\end{array}$ & $\begin{array}{l}\mathrm{V}(\mathrm{SD}) \\
(\mathrm{m} \mathrm{s}-1)\end{array}$ & $\begin{array}{l}\text { Vmax } \\
(\mathrm{m} \mathrm{s}-1)\end{array}$ & $\begin{array}{c}\mathrm{I} \\
(\mathrm{SD} / \mathrm{V})\end{array}$ \\
\hline \multirow{3}{*}{ Daily } & B & 9.0 & $8.0(1.0)$ & 9.1 & 0.06 & $8.7(1.9)$ & 10.2 & 0.08 \\
\hline & B2 & 4.5 & - & - & - & $7.2(1.8)$ & 9.1 & 0.13 \\
\hline & $\mathrm{C}$ & 15.0 & $7.2(1.0)$ & 8.5 & 0.09 & $7.2(1.8)$ & 9.1 & 0.13 \\
\hline \multirow{3}{*}{$\begin{array}{c}\text { Daytime } \\
(0600-1800)\end{array}$} & B & 9.0 & $8.1(0.9)$ & 9.3 & 0.06 & $8.9(1.6)$ & 10.2 & 0.07 \\
\hline & B2 & 4.5 & - & - & - & $7.5(1.5)$ & 9.2 & 0.11 \\
\hline & $\mathrm{C}$ & 15.0 & $7.4(0.8)$ & 8.7 & 0.09 & $7.5(1.5)$ & 9.2 & 0.11 \\
\hline \multirow{3}{*}{$\begin{array}{l}\text { Nighttime } \\
(1800-0600)\end{array}$} & B & 9.0 & $7.8(1.2)$ & 9.0 & 0.06 & $8.6(2.2)$ & 10.2 & 0.09 \\
\hline & B2 & 4.5 & - & - & - & $7.0(2.0)$ & 9.1 & 0.14 \\
\hline & $\mathrm{C}$ & 15.0 & $7.0(1.2)$ & 8.4 & 0.10 & $7.0(2.0)$ & 9.1 & 0.14 \\
\hline
\end{tabular}




\subsection{Wind Tunnel Experiments with Rocket Launching Pad (RLP) Model}

The atmospheric flow (wind profile, streamlines and wind vorticity) obtained in wind tunnel experiments for different geometries of the coastal cliff $\left(90^{\circ}, 110^{\circ}\right.$ and $135^{\circ}$ inclinations), including the presence of a RLP, are shown on Figure 8.
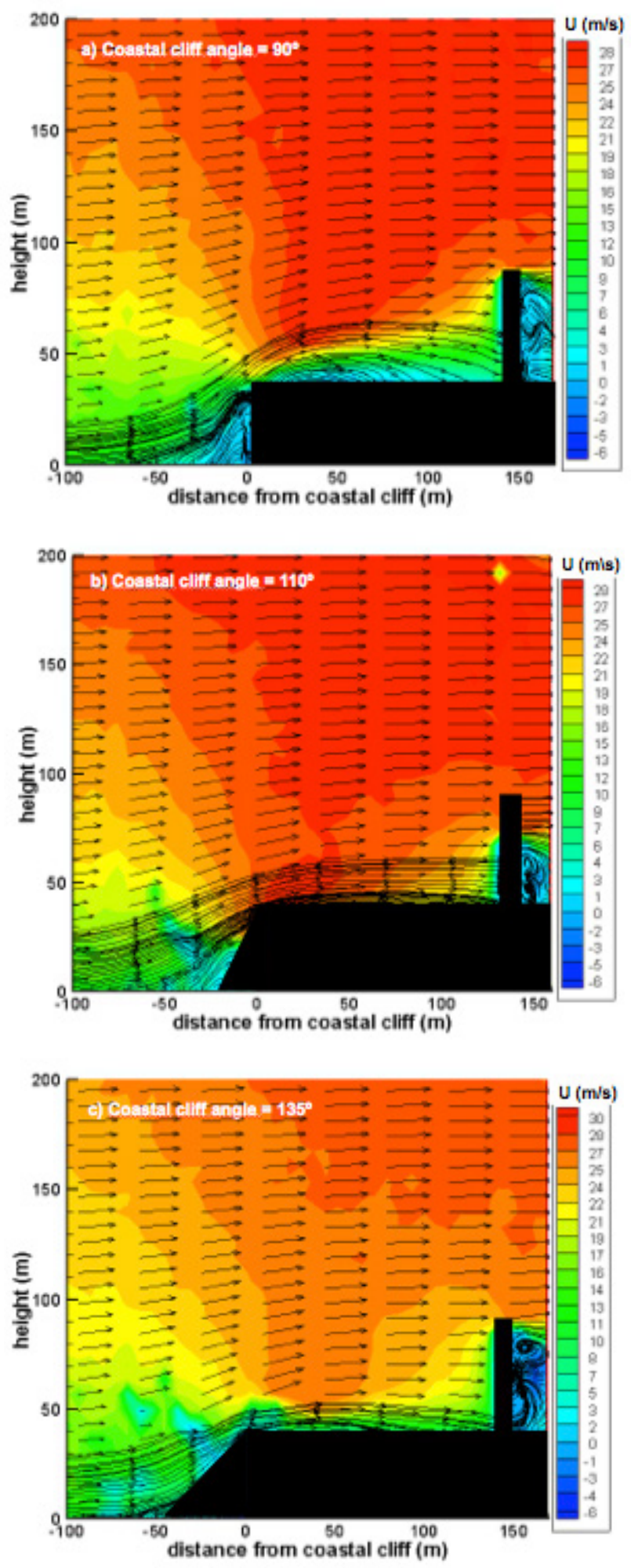
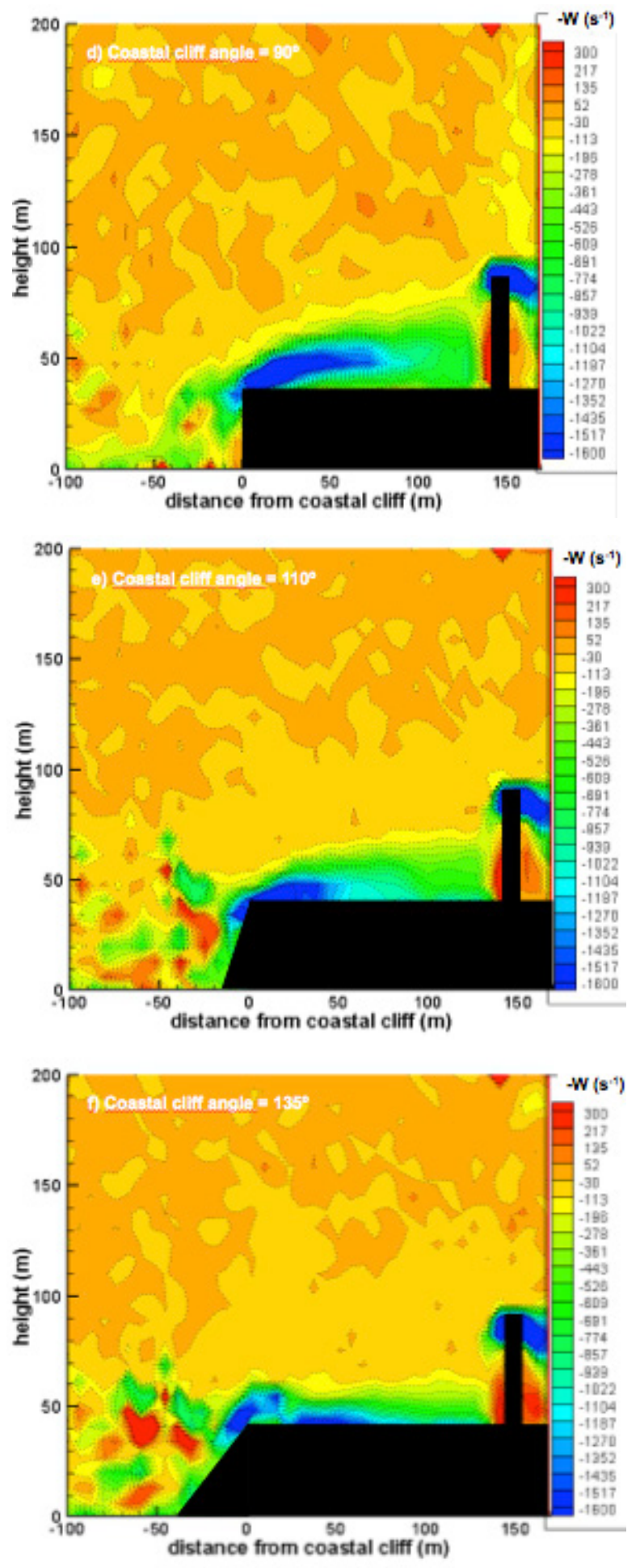

Figure 8. WT wind profiles, stream lines ( $a, b$ and $c$ ) and vorticity (d, e and f) for $90^{\circ}, 110^{\circ}$ and $135^{\circ}$ coastal cliffs and perpendicular wind direction

The geometry of the coastal cliff is a very important determinant of the flow and the turbulence. In all situations, there is the presence of a re-circulation zone. This zone is more intense (in terms of vertical depth and horizontal distance) for the $90^{\circ}$ inclination. It is interesting to notice that the IBL depth decouples the air above from the surface. In terms of turbulence/vorticities, the $90^{\circ}$ inclination generates 
high turbulence at the edge of the cliff and at the top of the RLP (located at $\mathrm{x}=150 \mathrm{~m}$ ), which is stronger than the other 2

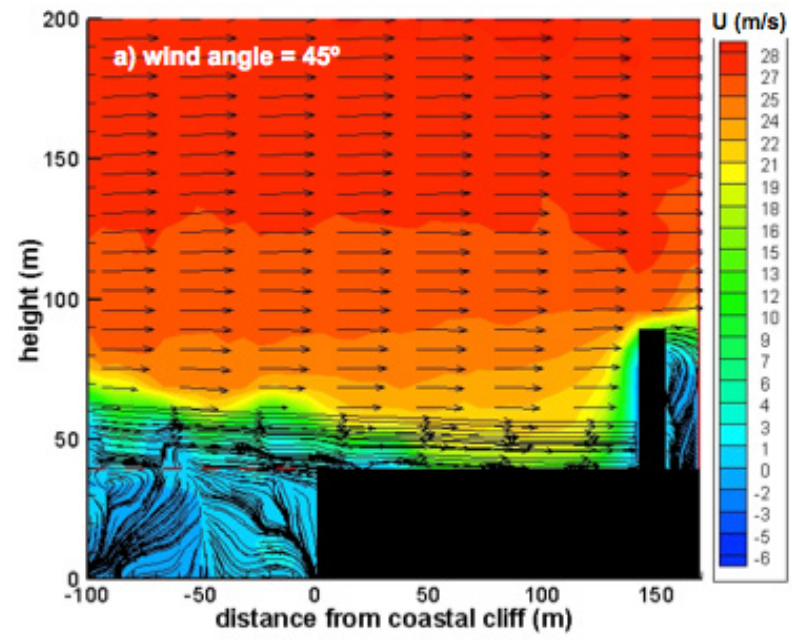

cases (for different geometries). The flow is not affected by the presence of RLP up to around $\mathrm{x}=100 \mathrm{~mm}$.

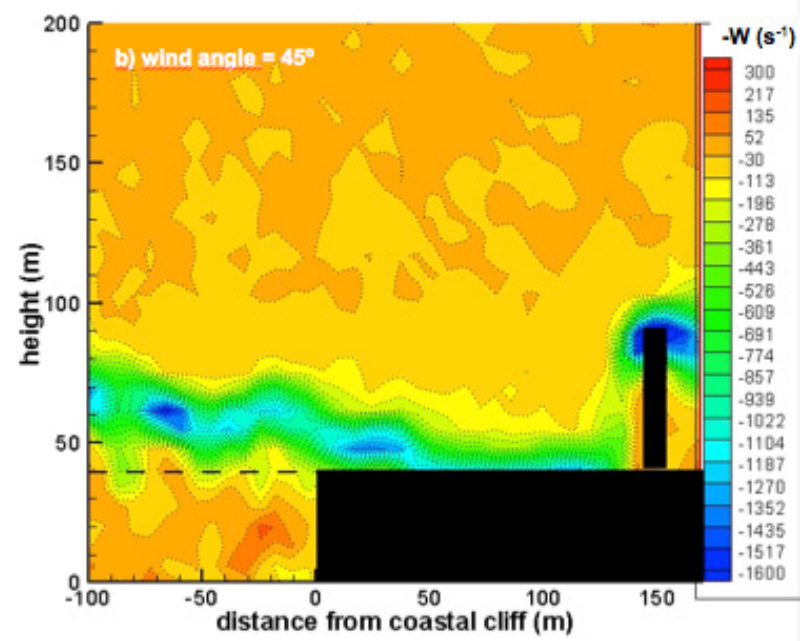

Figure 9. WT wind profiles, stream lines (a) and vorticity (b) for the $45^{\circ}$ wind direction

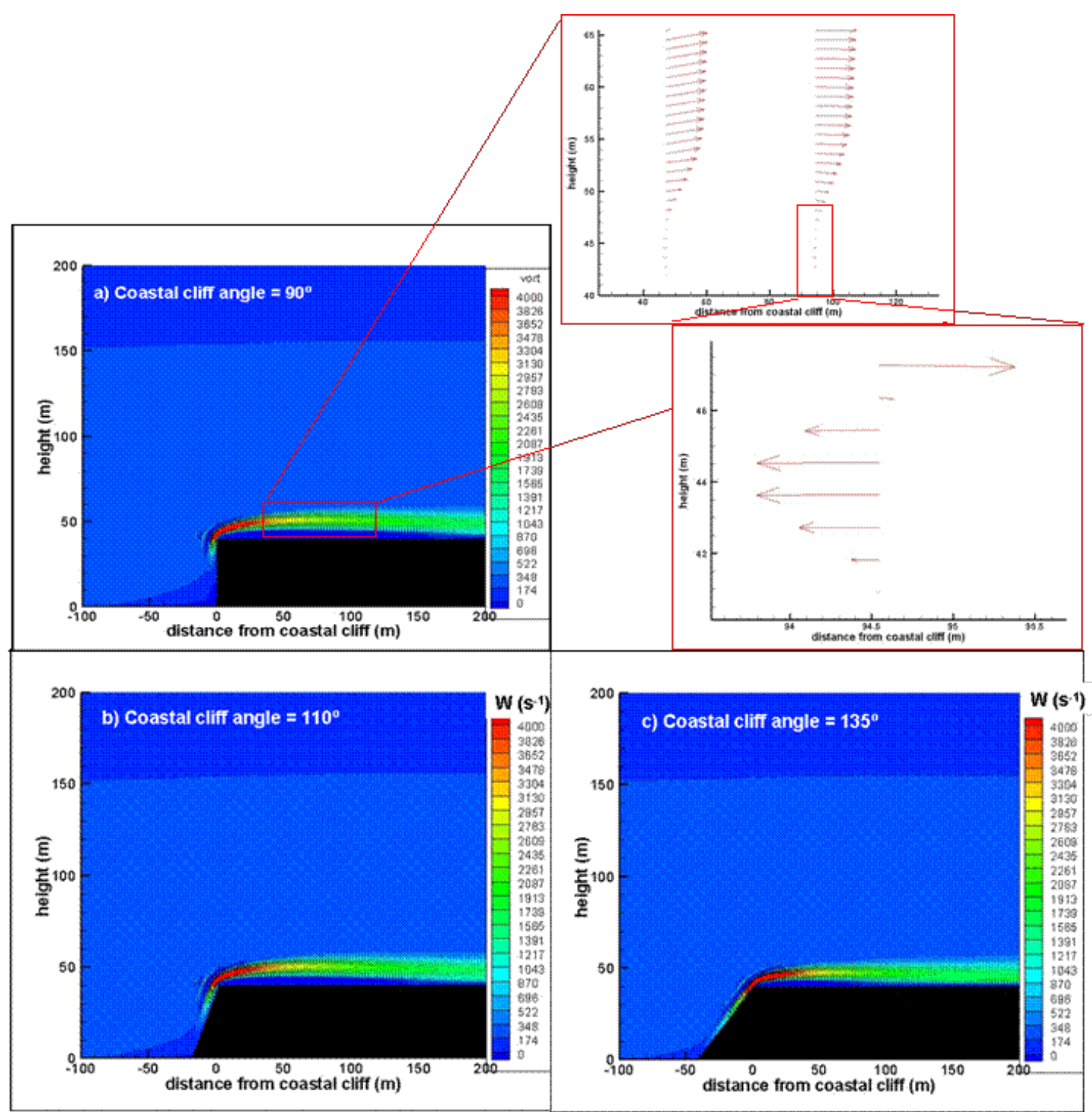

Figure 10. Numerical simulation of the wind vorticity and velocity $90^{\circ}, 110^{\circ}$ and $135^{\circ}$ coastal cliff 
Figure 9 presents the wind tunnel experiments for the predominant wind direction rotated by $45^{\circ}$ from the perpendicular flow to the coastal line. The re-circulation zone is very different from the previous case (Fig. 8). The IBL is not clearly created and it does not reach the RLP, situated at a distance of $150 \mathrm{~m}$. Regarding the vorticity field, the characteristic of the recirculation bubble generated by the edge of the coastal cliff is $1600 \mathrm{~s}-1$; however, the extension of the bubble decreases significantly with the incidence at sharp angles, compared to $90^{\circ}$, at which it is maximum.

This is probably due to the intrinsic tridimensionality of the flow when the wind flows are other than perpendicular to the coast, causing the existence of a nonzero lateral component of the velocity.

\subsection{Numerical Simulations}

The vorticity field and wind profiles obtained for $\mathrm{Re}=2.0$ $\mathrm{x} 107$ through the numerical simulations for all geometries $\left(90^{\circ}, 110^{\circ}\right.$ and $135^{\circ}$ inclinations of the cliff) are presented in Figure 10. The maximum vorticity ranges from $4000 \mathrm{~s}-1$ at the coastal cliff to $2000 \mathrm{~s}-1$ at $\mathrm{x}=150 \mathrm{~m}$ for all angles. The IBL demonstrated a height of $9 \mathrm{~m}$ at $\mathrm{x}=0 \mathrm{~m}, 17 \mathrm{~m}$ at $\mathrm{x}=50$ $\mathrm{m}, 21 \mathrm{~m}$ at $\mathrm{x}=100 \mathrm{~m}$ and $22 \mathrm{~m}$ at $\mathrm{x}=150 \mathrm{~m}$ for the $90^{\circ}$ inclination geometry. Making a zoom between $\mathrm{x}=50 \mathrm{~m}$ and $x=100 \mathrm{~m}$ (Fig. 10a), it is possible to observe a profile with inverse velocity, that denotes the recirculation inside the IBL.

At the point of $x=150 \mathrm{~m}$ (the location of the RLP), the IBL heights were $21 \mathrm{~m}$ for $110^{\circ}$ and $19 \mathrm{~m}$ for $135^{\circ}$, with a smaller recirculation and maximum vorticity around $1500 \mathrm{~s}^{-1}$. For inclination angles smaller than $90^{\circ}$ (not shown here but presented at Pires [44]), an increase of the IBL height, as well as the formation of a recirculation region before $\mathrm{x}=0$ are observed. For the angles $110^{\circ}$ and $135^{\circ}$ the recirculation region is almost nonexistent, being stronger for angles smaller than $90^{\circ}$. This behavior was also observed in the wind tunnel measurements $\left(\operatorname{Re}=7.5 \times 10^{4}\right)$.

\subsection{Observation, Numeric Simulation and Experiment Comparison}

Figure 11 compares the numerical simulations $(\operatorname{Re}=2.0 \mathrm{x}$ $\left.10^{7}\right)$, the wind tunnel experiments $\left(\mathrm{Re}=7.5 \times 10^{4}\right)$ and the ECLICLA 2 campaign results for an inclination of $90^{\circ}$. Also it shows their numerical expressions $a x^{b}$, with $\mathrm{R}^{2}$ equal to 0.9551 and 0.9709 , respectively, for the WT experiment and numeric simulation. Furthermore, adjusting the height of the WT experimental IBL with the same expression $(16.95 \mathrm{x}$ ${ }^{0.1948}$ ) for Re equal to $7.5 \times 10^{4}$ resulted in $\mathrm{R}^{2}=0.9259$ (in comparison with $\mathrm{R}^{2}=0.9551$ for the numeric simulations).

For $\operatorname{Re}=2.0 \times 10^{7}$, as there are only two height values obtained observationally, such a comparison cannot be made, but it shows a good approximation of the heights observed during the ECLICLAs with the numerical simulation. These results, together with Figure 6, which compares wind profiles observed in the AT with the corresponding numerical simulations, demonstrate the good quality of the numerical simulations for all cases considered.

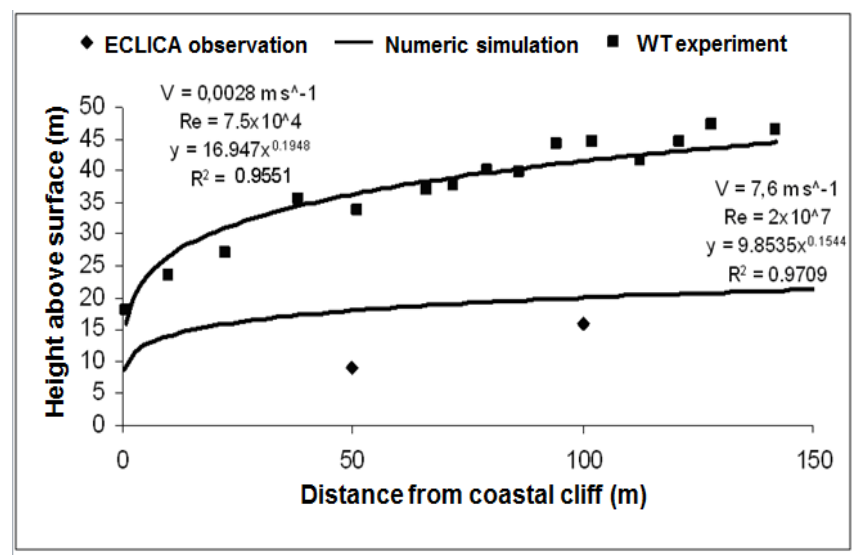

Figure 11. Comparison between observation, experiment and numerical simulation data

Table 2 shows the semi-empiric expressions derived by Equation 1, for different angles of the cliff. The roughness length $z_{0}$ used was $0.77 \mathrm{~m}$ as estimated by Fisch [12] and characteristic of the dry season at the ASC. The constant $a_{\mathrm{IBL}}$ varies from 16.1 to 47.6 for the wind tunnel experiments, and from 9.5 to 7.5 for the numerical simulation, and $b_{\mathrm{IBL}}$ is almost constant, around 0.2. The correlation coefficient $\left(\mathrm{R}^{2}\right)$ is good for the WT simulations for angles $90^{\circ}$ and $110^{\circ}$, but not for $135^{\circ}$. For numerical simulations, the $\mathrm{R}^{2}$ is around 0.97 and 0.99. However, in the literature there is a wide range for reported values of $a_{I B L}$ and $b_{I B L}$. Kallstrand and Smedman [29] suggest that the typical values for $a_{I B L}$ are between 2 and 5, and for $b_{I B L}$ stay around 0.5. According to Arya [24], the constant $a_{I B L}$ varies from 0.35 and 0.75 , while $b_{I B L}$ varies between 0.1 and 0.4 , depending on the surface.

Table 2. Values of $a, b$ and $R 2$ of adjusted power law IBL height

\begin{tabular}{|c|c|c|c|c|c|c|}
\hline & \multicolumn{3}{|c|}{$\begin{array}{c}\text { Wind Tunnel } \\
\text { Experiments } \\
\mathrm{Re}=7.5 \times 104\end{array}$} & \multicolumn{3}{c|}{$\begin{array}{c}\text { Numerical Simulations } \\
\mathrm{Re}=2.0 \times 107\end{array}$} \\
\hline Angles & $\mathrm{a}$ & $\mathrm{b}$ & $\mathrm{R} 2$ & $\mathrm{a}$ & $\mathrm{b}$ & $\mathrm{R} 2$ \\
\hline $90^{\circ}$ & 16.1 & 0.19 & 0.92 & 9.5 & 0.15 & 0.97 \\
\hline $110^{\circ}$ & 20.7 & 0.16 & 0.91 & 9.7 & 0.14 & 0.98 \\
\hline $135^{\circ}$ & 47.6 & 0.02 & 0.35 & 7.5 & 0.17 & 0.99 \\
\hline
\end{tabular}

\section{Conclusions and Final Comments}

The analyses of the observational points (data-set from ECLICLA) show that the point B presents the greatest values of the wind velocity, which is independent of the atmospheric stability (daytime or nighttime). This is an indication that the AT, which has most of its levels above the height of mast $\mathrm{B}$, is measuring the oceanic flow, as it is closer to the edge of the coastal cliff (similar to the point B mast).

The experimental test results from the wind tunnel show that the IBL can reach the RLP when the incident wind is perpendicular to the coastal cliff for all the inclination angles 
of the cliff. The different inclination angles of the coastal cliff do not affect the intensity of the vorticity; however, they cause alterations in the height of the IBL and influence the recirculation region: for the $90^{\circ}$ case, the recirculation region was smaller with the lowest IBL height; for inclination angles greater than $90^{\circ}$, the recirculation zone remains extensive, but with a reduction in the height of the IBL.

The numerical simulations show that IBL height for the $90^{\circ}$ and $135^{\circ}$ cliffs present the nearest values when compared with the values determined from the ECLICLA 2 observational data for the 50 and $100 \mathrm{~m}$ downwind distances from the nearly vertical cliff. Considering the situation of the coastal cliff with inclination of $90^{\circ}$, the IBL reaches the RLP at a height of $21 \mathrm{~m}$, while it is $19 \mathrm{~m}$ for the inclination of $135^{\circ}$. As the RLP is $20 \mathrm{~m}$ tall, it is significantly influenced by the IBL. The maximum vorticity generated on the coastal cliff of ASC is $4000 \mathrm{~s}^{-1}$ reaching the RLP with approximately 2000 $\mathrm{s}^{-1}$ which shows that the turbulence decreases with the distance from the edge of the cliff.

Concerning the semi-empiric expressions derived by Equation 1, the estimated values for $a_{I B L}$ are greater than the ones found in the literature (between 0.35 and 0.75 ) which relate to cases without topographic unevenness. In this case there is the formation of a recirculation zone starting from the windward slope, probably due to the turbulence generated by the coastal cliff. Concerning to the values for $b_{I B L}$ they are similar to the values found in the literature, varying between 0.1 and 0.4 .

In summary, although the observational data from ECLICLA are insufficient for a deeper analysis, the wind tunnel experiment presents a good tool for the general visualization of the flow, and provides a possible approach for investigation of the influence of the wind incident inclination angles on the flow beyond the coastal cliff. However, a more representative result with this tool may be obtained through a wind tunnel that reaches greater velocities and, consequently, Reynolds numbers closer to reality $\left(10^{7}\right)$. The validation of the WT and numerical simulations with observational data from the AT showed that even a two dimensional computational model represents well the atmospheric flow at ASC, probably due to the strong surface wind, which is a combination of trade winds and the sea breeze.

\section{ACKNOWLEDGEMENTS}

LBM Pires is grateful for support received from the "Conselho Nacional de Desenvolvimento Científico e Tecnológico" $(\mathrm{CNPq})$ for a doctoral fellowship (CNPq 141861/2006-1) and "Coordenacao de Aperfeicoamento de Pessoal de Nivel Superior" (CAPES) for a post-doctoral fellowship (13870-12-2). G Fisch is thankful for support from CNPq (Grants 559949/2010-3 and 303730/2010-7); LF Souza acknowledges the support of "Fundacao de Amparo a Pesquisa do Estado de Sao Paulo" (FAPESP) (process 04/16064-9). The authors would like to thank the technicians
Jose Rogerio Banhara and Jose Ricardo Carvalho de Oliveira, both from the Aerodynamics Division, ALA, for their valuable help in this research.

\section{REFERENCES}

[1] Marinho, L.P.B., Avelar, A.C., Fisch, G., Roballo, S.T., Souza, L.F., Gielow, R. and Giradi, R.M., 2009, Studies using wind tunnel to simulate the Atmospheric Boundary Layer at the Alcântara Space Center, J. Aerosp. Technol. Manag., 91-98

[2] Uccellini, L.W., Brill, K.F., Petersen, R.A., Keyser, D., Aune, R., Kocin, P.J. and des Jardins, M., 1986, A report on the upper-level wind conditions preceding and during the shuttle Challenger (STS 51 L) explosion, Bull. Am. Meteorol. Soc., 67:1248-1265. doi: http://dx.doi.org/10.1175/1520-0477(198 6)067<1248:AROTUL $>2.0 . \mathrm{CO} ; 2$.

[3] Fichtl, G.H., Reynolds, N.D., Johnston, A.E., Adelfang, S.I., Batts, W., Lott, L., Meyer, P.J., Smith, O.E., Swint, M.S. and Vaughan, O.H.Jr., 1988, Analysis of in-flight winds for shuttle mission STS 51-L, J. Appl. Meteorol., 27:1232-1241. doi: http://dx.doi.org/10.1175/1520-0450(1988)027<1232:A OIFWF $>2.0 . \mathrm{CO} ; 2$.

[4] Winters, K.A., Roeder, W.P., Madura, J.T., Herrings, H.C., 2004, Use of Archived Weather Data from Spaceport Florida in Support of Space Shuttle Columbia Accident Investigation, 14th Conference on Applied Climatology, 84th AMS Annual Meeting, Seattle, US, paper 71189.

[5] Bellue, D.G., Boyd, B.F., Vaughan, W.W., Madura, J.T., Garner, T., Winter, K.A., Weems, J.W. and Herring, H.C., 2006, Shuttle weather support from design to launch to return to flight, 12th Conference on Aviation, Range and Aerospace Meteorology, 86th AMS Annual Meeting, Atlanta, US, paper 101298.

[6] Kingwell, J., Shimizu, J., Narita, K., Kawabata, H. and Shimizu, I., 1991, Weather factors affecting rocket operations: a review and case history, Bull. Am. Meteorol. Soc., 72:778-793. doi: http://dx.doi.org/10.1175/1520-0477(1991) $072<0778$ :WFAROA $>2.0 . \mathrm{CO} ; 2$

[7] Fisch, G., 1999, Características do perfil vertical do vento no Centro de Lançamento de Foguetes de Alcântara (CLA), Rev. Bras. Meteorol., 14:11-21.

[8] Jonhson, D.L., 2008, Terrestrial environment (climatic) criteria guidelines for use in aerospace vehicle development, Huntsville, NASA/TM 2008-215633, CD-ROM.

[9] Vaughan, W.W. and Johnson, D.C., 2010, Aerospace meteorology: some lessons learned. 14th Conference on Aviation, Range and Aerospace Meteorology, 90th AMS Annual Meeting, Atlanta, US, paper 157285.

[10] Kwon, K.J., Lee, J.Y. and Sung, B., 2003, PIV Measurements on the boundary Layer Flow around Naro Space Center, 5th International Symposium on Particle Image Velocimetry, Busan, Korea, PIV'03 Paper 3121.

[11] Fisch, G., 2003, Análise da turbulência atmosférica no Centro de Lançamento de Foguetes de Alcântara, Rev. Ciência e Natura, 211-215. 
[12] Fisch, G., 2005, Análise do perfil de vento no Centro de Lançamento de Alcântara, Rev. Ciência e Natura, 171-175.

[13] Roballo, S.T. and Fisch, G., 2008, Escoamento atmosférico no Centro de Lançamento de Alcântara (CLA): Parte I Aspectos Observacionais, Rev. Bras. Meteorol., 23:510 -519. doi:10.1590/S0102-77862008000400010

[14] Roballo, S.T., Fisch, G. and Girardi, R.M., 2009, Atmospheric flow at the Alcantara Lauching Center (ALC): part II - experiments at a wind tunnel, Rev. Bras. Meteorol., 24. doi http://dx.doi.org/10.1590/S0102-7786200900010000 9.

[15] Jackson, P.S. and Hunt, J.C.R., 1975, Turbulent wind flow over a low hill, Quart. J. R. Met. Soc, 101:929-955.

[16] Britter, R.E., Hunt, J.C.R. and Richards, K.J., 1981, Air flow over a two-dimensional hill: studies of velocity speed-up, roughness effects and turbulence, Quart. J. R. Met. Soc., 107:91-110

[17] Hunt, J.C.R. and Snyder, W.H., 1980, Experiments on stably and neutrally stratified flow over a model three-dimensional hill, J. Fluid Mech., 98:671-704.

[18] Hunt, J.C.R., Puttock, J.S. and Snyder, W.H., 1979, Turbulent diffusion from a point source in stratified and neutral flows around a three-dimensional hill - Part I. Diffusion equations analysis, Atm. Environment, 13:1227-1239.

[19] Snyder, W.H., Thompson, R.S., Eskridge, R.E., Lawson, R.E., Castro, I.P., Lee, J.T., Hunt, J.C.R. and Ogawa, Y., 1985, The structure of strongly stratified flow over hills: dividing-streamline concept., J. Fluid Mech, 152: 249-288. doi: http://dx.doi.org/10.1017/S0022112085000684.

[20] Sheppard, P.A., 1956, Airflow over mountains, Quart. J. R. Met. Soc., 82:159-161.

[21] Sherry, M.J., Jacono, D.L., Sheridan, J., Mathis, R. and Marusic, I., 2009, Flow Separation Characterisation of a forward facing step immersed in a turbulent boundary layer, Proceedings Sixth International Symposium on Turbulence and Shear Flow Phenomena Seoul, Korea, 22-24 June 2009.

[22] Pearson, D.S., Goulart, P.J. and Ganapathisubramani, B., 2011, Investigation of turbulent separation in a forward-facing step flow, 13th European Turbulence Conference ETC13, J. Phys: Conf Series 318 (2011) 022031. doi:10.1088/1742-6596/318/2/022031.

[23] Stull, R., 1988, An introduction to boundary layer meteorology, Kluwer, London.

[24] Arya, S.P., 2001. Introduction to micrometeorology, Academic Press, San Diego.

[25] Elliott, W.P., 1958, The growth of the atmospheric internal boundary layer, Trans. Am. Geophys. Union, 39:1048-1054. doi: 10.1029/TR039i006p01048.

[26] Pendergrass, W. and Arya, S.P., 1984, Dispersion in neutral boundary layer over a step change in surface roughness - I. Mean flow and turbulence structure, Atm. Enviroment, 18:1267-1279.

[27] Sempreviva, A.M., Larsen, S.E., Mortensen, N.G. and Troen, I., 1990, Response of neutral boundary layers to change of roughness, Boundary-Layer Meteorol., 50:205-225.
[28] Sugita, M. and Brutsaert, W., 1990, Wind velocity measurements in the neutral boundary layer above Hilly Prairie, J. Geophys. Res., 95:7617-7624.

[29] Källstrand, B. and Smedman, A.S., 1997, A case study of the near-neutral coastal internal boundary-layer growth: aircraft measurements compared with different model estimates, Boundary-Layer Meteorol., 85:1-33.

[30] Jegede, O.O. and Foken, T., 1998, A study of the internal boundary dayer due to a roughness change in neutral conditions observed during the LINEX field campaigns, Theor. Appl. Climatol., 62:31-41.

[31] Savelyev, S.A. and Taylor, P.A., 2005, Internal boundary layers: I. height formulae for neutral and diabatic flows, Boundary-Layer Meteorol., 115:1-25.

[32] Garratt, J.R., 1992, The Atmospheric Boundary Layer, Cambridge: Cambridge University Press. 316.

[33] Batchvarova, E. and Gryning, S.E., 1998, Wind climatology, atmospheric turbulence and internal boundary-layer development in Athens during the Medcaphot-Trace Experiment, Atm. Environment, 32:2055-2069.

[34] Liu, H., Chan, J.C.L. and Cheng, A.Y.S., 2000, Internal boundary layer structure under sea-breeze conditions in Hong Kong, Atm. Environment, 35:683-692.

[35] Hara, T., Ohya, Y., Uchida, T. and Ohba, R., 2009, Wind-tunnel and numerical simulations of the coastal thermal internal boundary layer, Boundary-Layer Meteorol., 130:365-381.

[36] Loredo-Souza, A.M., Schettini, E.B.C and Paluch, M.J., 2004, Simulação da camada limite atmosférica em túnel de vento In: Möler SM, Silvestrini J, IV Turbulência, Porto Alegre, Brasil, 4:137-163.

[37] Berg, J., Mann, J., Bechmann, A., Courtney, M. and Jorgensen, H., 2011, The Bolund experiment, part I: flow over a steep, three-dimensional hill, Boundary-Layer Meteorol., 141:219-243. doi 10.1007/s10546-011-9636-y.

[38] Pires, L.B.M., de Paula, I.B., Fisch, G., Gielow, R. and Girardi, R.M., 2013, Simulations of the Atmospheric Boundary Layer in a Wind Tunnel with Short Test Section. J. Aerosp. Technol. Manag., 5:305-314. doi: 10.5028/jatm. v5i3.190.

[39] Degrazia, G.A. and Goulart, A.G.O, 2004, Turbulência e dispersão de contaminantes na Camada Limite Planetária. IV Escola de Primavera Transição e Turbulência EPTT-4, pp. 73-108.

[40] Pires, L.B.M., Souza, L.F., Fisch, G. and Gielow, R., 2009, La Influencia de la Altura de la Capa Límite Oceánica en la Región del Centro de Lanzamientos de Alcántara en Brasil. Información Tecnológica, 20:119-128. doi: 10.1612/inf.tecn ol.4071it.08.

[41] Reuter, E.D.J., Fisch, G., Mota, G.V. and Cohen, J.C.P., 2004, Estudo observacional da Camada Limite Planetária Marinha na região do Centro de Lançamento de Foguetes de Alcântara - MA, Rev. Bras. de Meteorol., 19:251-264.

[42] Simpson, J.E., 1994, Sea breeze and local wind, Cambridge University Press. 
[43] Azevedo, L.F.A. and Almeida, J.A., 2002, Velocimetria por Imagem de Partículas. III Escola de Primavera em Transição e Turbulência EPTT-3, pp. 191-214.

[44] Pires, L.B.M., 2009, Estudo da camada limite interna desenvolvida em falésias com aplicação para o Centro de Lançamento de Alcantara. Tese (Doutorado em Meteorologia) Instituto Nacional de Pesquisas Espaciais, INPE, São José dos Campos, 165p. (INPE-16566-TDI/1562). http://pct.capes.go v.br/teses/2009/33010013003P8/TES.PDF.

[45] Góis, E.R.C. and Souza, L.F., 2007, Numerical study of lock-in phenomena in 2D flow over a Cylinder. XII International Symposium on Dynamic Problems of Mechanics DINAME 2007. Varoto, P.S. and Trindade, M.A. (editors), ABCM, Brazil.

[46] Souza, L.F., 2005, Numerical simulation of a flow over a circular cylinder using immersed boundary method in vorticity-velocity formulation. Procedings of 18th International Congress of Mechanical Engineering COBEM Brazil.

[47] Peskin, C.S., 1972, Flow patterns around heart valves: A numerical method, J. Comp. Phys., 10:252-271.

[48] Pires, L.B.M., Souza, L.F., Fisch, G. and Gielow, R., 2011, Numerical study of the atmospheric flow over a coastal cliff, Int. J. Num. Meth. Fluids., 67(5):599-608. doi: 10.1002/ fld. 2377 . 